\title{
INHIBITION OF LIPID PEROXIDATION WITH THE LAZAROID U74500A ATTENUATES ISCHEMIA- REPERFUSION INJURY IN A CANINE ORTHOTOPIC HEART TRANSPLANTATION MODEL
}

Yoshihisa Tanoue, MD

Shigeki Morita, MD

Yoshie Ochiai, MD

Manabu Hisahara, MD

Munetaka Masuda, MD

Yoshito Kawachi, MD

Ryuji Tominaga, MD

Hisataka Yasui, MD
Background: The lazaroid U74500A is a 21-aminosteroid that inhibits lipid peroxidation and attenuates ischemia-reperfusion injury. We examined the effect of $\mathrm{U7500A}$ on heart preservation with the use of a clinically relevant canine orthotopic heart transplantation model. Methods and results: Six donor dogs (group L) were pretreated intravenously with U74500A (10 $\mathrm{mg} / \mathrm{kg}$ ), and the dogs without pretreatment served as a control (group C, $n=6$ ). The donor heart was preserved in cold University of Wisconsin solution for 24 hours. The heart was then transplanted orthotopically. Myocardial biopsy was performed to measure the adenosine triphosphate level at the end of ischemia. Before reperfusion, recipients in group $L$ received another dose of $\mathrm{U} 74500 \mathrm{~A}(10 \mathrm{mg} / \mathrm{kg})$ intravenously. After 3 hours of reperfusion, left ventricular function was evaluated by left ventricular pressure-volume relations with the use of a Millar catheter and conductance catheter, thereby deriving the slope of the end-systolic pressurevolume relation, the slope of the stroke work-end-diastolic volume relation, and the slope of the maximum $\mathrm{dP} / \mathrm{dt}$-end-diastolic volume relation. At the same time, serum creatine kinase $M B$ isoenzyme and lipid peroxide levels were measured. The slopes of the end-systolic pressure-volume relation, the stroke work-end-diastolic volume relation, and the maximum $\mathrm{dP} / \mathrm{dt}$-enddiastolic volume relation for group $L$ were significantly higher than those for group $C$. The adenosine triphosphate levels for group $L$ were significantly higher than those for group $C$. Serum creatine kinase MB isoenzyme and lipid peroxide levels for group $L$ were significantly lower than those for group C. Conclusions: Inhibition of lipid peroxidation by the administration of U74500A was effective for 24-hour canine cardiac preservation. These results indicate that $\mathrm{U} 74500 \mathrm{~A}$ is a promising agent for heart allograft preservation. (J Thorac Cardiovasc Surg 1996;112:1017-26)
C ardiac transplantation is lifesaving for more than 3000 patients with end-stage heart diseases every year. ${ }^{1}$ Unfortunately, its application is limited by the scarcity of donors. Adequate preservation of the cardiac allograft during the ischemic period is of paramount inportance because of the increasingly

From the Department of Cardiovascular Surgery, Faculty of Medicine, Kyushu University, Fukuoka, Japan.

Supported in part by grant-in-aid for scientific research 07671479 from the Ministry of Education, Science, and Culture, Tokyo.

Received for publication Jan. 24, 1996; revisions requested Feb. 29, 1996; revisions received March 21, 1996; accepted for publication March 26, 1996

Address for reprints: Shigeki Morita, MD, Department of Cardiovascular Surgery, Faculty of Medicine, Kyushu University, 3-1-1 Maidashi, Higashi-ku, Fukuoka 812-82, Japan.

Copyright (c) 1996 by Mosby-Year Book, Ine.

$0022-5223 / 96 \$ 5.00+0 \quad \mathbf{1 2 / 1 / 7 3 7 8 4}$ longer travel times for donor organs and the limited supply of donors.

Despite improvements in graft preservation, surgical technique, and transplantation immunology, the clinically acceptable ischemic time for heart grafts remains 6 hours, and the prolonged ischemic time is one of the risk factors for 1-year heart transplantation mortality. ${ }^{1}$ Ischemia-reperfusion injury is the cause of the cardiac dysfunction of transplanted hearts. ${ }^{2-4}$ The accumulation of oxygenderived free radicals and lipid peroxidation induced by oxygen-derived free radicals are associated with the occurrence of ischemia-reperfusion injury. A number of oxygen-derived radical scavengers and lipid peroxidation inhibitors have been developed to reduce ischemia-reperfusion injury after heart transplantation. $^{5-10}$

A novel series of 21-aminosteroids called laz- 
aroids prevent lipid peroxidation without obvious glucocorticoid or mineralocorticoid side effects, ${ }^{11,12}$ They have been effective therapeutic agents for acute central nervous system ischemia. ${ }^{13,14} \mathrm{We}^{15-17}$ previously reported that the inhibition of lipid peroxidation by U74500A, one of the lazaroid family, is beneficial for attenuating ischemia-reperfusion injury of heart and lung in a variety of models. For this agent to be applied for human heart transplantation, experiments that use large animals are necessary. This study describes the in vivo efficacy of the prevention of lipid peroxidation with U74500A in the canine orthotopic heart transplantation model.

\section{Materials and methods}

Donor preparation. Twelve adult mongrel dogs were divided randomly into two groups: the lazaroid-administered group (group L) and the control group (group C). All donor dogs were anesthetized with sodium pentobarbital (30 mg/kg intravenously), followed by atropine sulfate $(0.04 \mathrm{mg} / \mathrm{kg}$ intramuscularly). They were then intubated with an $8.5 \mathrm{~F}$ endotracheal tube. Mechanical ventilation was instituted with a tidal volume of $25 \mathrm{ml} / \mathrm{kg}$ at a rate of 12 breaths/min, with a positive end-expiratory pressure of $5 \mathrm{~cm} \mathrm{H}_{2} \mathrm{O}$, and with an inspired oxygen fraction of 1.0. The dogs were placed in a supine position. Pancuronium bromide was administered intravenously for muscle relaxation. A continuous infusion of sodium pentobarbital was used to maintain anesthesia. An antibiotic, flomoxef $(25 \mathrm{mg} / \mathrm{kg}$ intravenously), was administered to prevent infection. Systemic blood pressure was continuously monitored by a right femoral arterial catheter.

After a median sternotomy, the ascending aorta, the main pulmonary artery, both venae cavae, and the aortic arch were isolated, and the azygos vein was ligated. A catheter-tip micromanometer (model MPC-500, Millar Instruments, Inc., Houston, Tex.) was inserted into the left atrial appendage for the left atrial pressure measurement, and a $14 \mathrm{~F}$ ultrasonic flow probe (Transonic Systems, Inc., New York, N.Y.) was positioned around the ascending aorta for the measurement of aortic flow. Aortic flow was measured at the left atrial pressure of 7 $\mathrm{mm} \mathrm{Hg}$ for the assessment of cardiac function of the pretransplantation donor heart. Heparin sodium (500 $\mathrm{U} / \mathrm{kg}$ intravenously) was administered systemically, and a modified 14F double-lumen cannula (Retroplegia Coronary Sinus Cardioplegic Cannula, Research Medical, Inc., Midvale, Utah) was inserted through the brachiocephalic artery to the aortic root. After an intravenous infusion of Ringer's lactate solution, 800 to $1000 \mathrm{ml}$ of blood was removed from the cannula. The blood was later used to prime the heart-lung machine for the recipient operation. During blood removal, the aortic root pressure was continuously monitored to maintain the pressure above 80 $\mathrm{mm} \mathrm{Hg}$.

Six donor dogs in group $\mathrm{L}$ were pretreated with U74500A ( $10 \mathrm{mg} / \mathrm{kg}$ intravenously) 15 minutes before the heart was arrested, and six donor dogs in group $\mathrm{C}$ without pretreatment served as the control subjects. U74500A was solved in a CS-4 solution (citric acid monohydrate, 0.02 $\mathrm{mol} / \mathrm{L}$; sodium citrate dihydrate, $0.0032 \mathrm{~mol} / \mathrm{L} ; \mathrm{NaCl}$, $0.077 \mathrm{~mol} / \mathrm{L}$; The Upjohn Co., Kalamazoo, Mich.). After the aorta was crossclamped between the brachiocephalic artery and the left subclavian artery, the hearts of all donor dogs were arrested by the infusion of cold crystalloid cardioplegic solution $\left(\mathrm{K}^{+}, 20 \mathrm{mmol} / \mathrm{L} ; \mathrm{Na}^{+}, 87\right.$ $\mathrm{mmol} / \mathrm{L} ; \mathrm{Ca}^{2+}, 0.1 \mathrm{mmol} / \mathrm{L} ; \mathrm{Cl}^{-}, 97 \mathrm{mmol} / \mathrm{L} ; \mathrm{HCO}_{3}{ }^{-}, 10$ $\mathrm{mmol} / \mathrm{L}$; glucose, $25 \mathrm{gm} / \mathrm{L}$ ) used in the Kyushu University Hospital. ${ }^{18}$ Fifteen milliliters of solution per kilogram of body weight was infused over 2 minutes with a rotating pump (Mera blood pump HCP-100, Senko Medical Instrument, Tokyo, Japan). The left atrial appendage was amputated, and the inferior vena cava was opened to decompress the heart. The hearts were then flushed with the same amount of University of Wisconsin (UW) solution (ViaSpan, DuPont Pharmaceuticals, Wilmington, Del.) over 2 minutes. The temperature of the solution was maintained at $4^{\circ} \mathrm{C}$ by a heat exchanger (Mera Hot \& Cool Unit MSH-51, Senko Medical Instrument, Tokyo, Japan). The hearts were removed with a standard technique, placed in a plastic bag containing cold UW solution, and preserved at $1^{\circ} \mathrm{C}$ for 24 hours.

Recipient preparation. After 24 hours, the hearts were transplanted to 12 weight-matched recipient dogs by a standard technique of orthotopic heart transplantation. All recipient dogs were anesthetized and pretreated in the same manner as the donor dogs, and the recipients received $500 \mathrm{mg}$ of methylprednisolone intravenously and $50 \mathrm{mg}$ of indomethacin rectally after induction. Sodium pentobarbital was drip-infused intravenously to maintain anesthesia. Systemic blood pressure was continuously monitored by a right femoral arterial catheter.

All recipients were placed in a supine position. After a median sternotomy, the pericardium was incised and fashioned into a cradle. The ascending aorta, the main pulmonary artery, and both venae cavae were isolated, and the azygos vein was ligated. A heart-lung machine consisted of a centrifugal pump (Bio-pump BP-80, Medtronic Bio-Medicus, Eden Prairie, Minn.), and a membrane oxygenator (D705 Midiflo System, Dideco, Milandola, Italy) was primed with the blood from the donor dog. After the administration of heparin $(500 \mathrm{U} / \mathrm{kg}$ intravenously), cardiopulmonary bypass with moderate hypothermia was instituted through thin-walled, angled metal venous cannulas (20F Pacifico Venous Cannula, DLP, Grand Rapids, Mich.) through the superior and inferior venae cavae and an arterial cannula $(3.8 \mathrm{~mm}$ high flow aortic arch cannula, Sarns/3M Health Care, Ann Arbor, Mich.) through the ascending aorta.

After crossclamping of the ascending aorta, the recipient heart was removed, and the donor heart was transplanted. The anastomosis was performed in the order of the left atrium, the right atrium, the main pulmonary artery, and the ascending aorta. A continuous over-andover suture of 4-0 polypropylene suture was used for the left and right atrial suture, and 5-0 polypropylene suture was used for the main pulmonary artery and the ascending aorta. The left ventricle was vented with a $12 \mathrm{~F}$ thin walled catheter (Kuraray Co., Okayama, Japan) through the left atrial appendage. The donor hearts were topically cooled with ice slush during the procedure. After completion of 
the right atrial and main pulmonary arterial anastomoses, the hearts were flushed with a $5 \mathrm{ml} / \mathrm{kg}$ concentration of $4^{\circ} \mathrm{C}$ crystalloid cardioplegic solution.

Before reperfusion, recipients in group $\mathrm{L}$ received another dose of U74500A (10 mg/kg intravenously). The aorta was declamped, the air was removed from the aorta and the left ventricle, and the heart was electrically defibrillated, if necessary. Fifteen minutes after reperfusion, calcium chloride was received to correct serum calcium level, and 30 minutes after reperfusion, ventricular pacing was instituted with a rate of 140 to 150 beats/min. All recipients were disconnected from cardiopulmonary bypass 60 minutes after reperfusion without inotropic or vasodilatory agents.

A right heart bypass preparation was then established as follows. ${ }^{19,20} \mathrm{~A}$ purse-string suture was placed at the right ventricular outflow tract, and a $16 \mathrm{~F}$ arterial cannula (William Harvey arterial perfusion cannulas, C.R. Bard, Inc., Tewksbury, Mass.) was inserted into the main pulmonary artery. The tapes around the superior and inferior venae cavae were snared to direct systemic venous blood return into a reservoir. The blood oxygenated with a membrane oxygenator was pumped back to the main pulmonary artery. Pulmonary valvular regurgitation was prevented by snaring the tape around the main pulmonary artery. Another $12 \mathrm{~F}$ thin walled catheter was placed in the right ventricle through the right atrium to drain the entire coronary venous return for the flow measurement and the oximetry. Coronary flow was measured by an in-line electromagnetic flow probe (Nihon Kohden, Tokyo, Japan). To measure the left ventricular ( $\mathrm{LV}$ ) volume, a purse-string suture was placed at the LV apex, and an $8 \mathrm{~F}$ eight-electrode conductance catheter (Webster, Inc., Baldwin Park, Calif.) was inserted into the left ventricle through the apex, and the tip of the catheter was positioned just above the aortic valve. The catheter was attached to a signal generator-processor (Sigma 5, Leycom, Oegstageest, The Netherlands). ${ }^{21-23}$ A catheter-tip micromanometer was inserted into the left ventricle for the LV pressure measurement, and the LV pressurevolume loop was then measured. A $14 \mathrm{~F}$ ultrasonic flow probe was positioned around the ascending aorta for the measurement of aortic flow to calibrate the volume signal of the conductance catheter. To control the $\mathrm{LV}$ venous return and to completely decompress the right ventricle, right heart bypass was instituted, thereby eliminating parallel conductance variation.

The heart rate was fixed at 140 to 150 beats/min by pacing during the assessment period. All signals (e.g., electrocardiogram, pressures, flows, volume) were continuously monitored on a multichannel oscillograph (polygraph 360 system, NEC Sanei, Tokyo, Japan) and on-line digitized at $200 \mathrm{~Hz}$ with an analog-to-digital converter (MacLab System, ADInstruments, Ltd., Dunedin North, New Zealand) and recorded on a digital computer (Macintosh Quadra 700, Apple Computer, Inc., Cupertino, Calif.).

After the study, all dogs were killed by means of an overdose of intravenous sodium pentobarbital and potassium chloride. The heart was removed from the chest, and the right ventricle and the left ventricle (free wall plus septum) were weighed. LV free wall specimens were taken for the myocardial water content measurement.

Data analysis

Conventional hemodynamic variables. At 90, 120, 150, and 180 minutes after reperfusion, conventional hemodynamic variables (i.e., heart rate, left atrial pressure, mean aortic pressure, and aortic flow) were obtained. The left atrial pressure was maintained around $10 \mathrm{~mm} \mathrm{Hg}$ during the assessment period.

Volume signal calibration. Conductance catheter volumes were calibrated by cardiac output (the amount of aortic flow and coronary flow). ${ }^{23}$ The parallel conductance volume was calculated by transiently altering blood conductivity by the injection of hypertonic saline solution ( 5 $\mathrm{ml}$ of $10 \% \mathrm{NaCl}) .^{21,22}$

Ventricular function. At 90,120,150, and 180 minutes after reperfusion, multiple LV pressure-volume loops were obtained during transient preload reduction by reducing right heart bypass flow for the assessment of $\mathrm{LV}$ contractility and stiffness. The digitized data were analyzed by computer algorithms with a C-language-type program developed in our laboratory with an Intel 486 personal computer (Vision, IBM Japan, Tokyo, Japan). LV contractility was assessed by the end-systolic pressurevolume (Pes-Ves) relation, ${ }^{24}$ the stroke work-end-diastolic volume (SW-Ved) relation, ${ }^{25}$ and the maximum $\mathrm{dP} / \mathrm{dt}-$ Ved $\left(\mathrm{dP} / \mathrm{dt}_{\max }-\mathrm{Ved}\right)$ relation. ${ }^{26,27}$ The Pes-Ves relation was fit by linear regression to obtain a slope (Ees) and volume intercept $\left(\mathrm{V}_{0}\right.$, es $)$ as follows:

$$
\text { Pes }=\text { Ees }\left(\text { Ves }-V_{0}, \text { es }\right)
$$

To quantify the position of the Pes-Ves relation in the operating range, the volume $\left(\mathrm{V}_{100}\right.$,es) associated with a Pes of $100 \mathrm{~mm} \mathrm{Hg}$ was calculated as follows:

$$
\mathrm{V}_{100} \text {, es }=\mathrm{V}_{0} \text {, es }+100 / \text { Ees }
$$

SW was calculated as the area of each pressure-volume loop and was plotted against Ved as follows:

$$
\mathrm{SW}=\mathrm{M}_{\mathrm{SW}}\left(\mathrm{Ved}-\mathrm{V}_{0, \mathrm{SW}}\right)
$$

$\mathrm{M}_{\mathrm{SW}}$ is the slope of the SW-Ved relation and $\mathrm{V}_{0 . \mathrm{SW}}$ is the volume intercept of the SW-Ved relation. End-diastolic point was defined as the point of the rapid upstroke of the first derivative of the $L V$ pressure $(\mathrm{dP} / \mathrm{dt})$. The position of the $S W-V e d$ relation in the operating range was calculated by determining Ved associated with SW of $500 \mathrm{~mm} \mathrm{Hg} \cdot \mathrm{ml}$ :

$$
\mathrm{V}_{500, \mathrm{SW}}=\mathrm{V}_{0, \mathrm{SW}}+500 / \mathrm{M}_{\mathrm{SW}}
$$

$\mathrm{dP} / \mathrm{dt}_{\max }$ and $V$ ed were fit to

$$
\mathrm{dP} / \mathrm{dt}_{\max }=\mathrm{dE} / \mathrm{dt}_{\text {max }}\left(\text { Ved }-\mathrm{V}_{0, \mathrm{dP} / \mathrm{dt}}\right)
$$

In these equations, $\mathrm{dE} / \mathrm{dt}_{\max }$ is the slope of the $\mathrm{dP} /$ $\mathrm{dt}_{\mathrm{max}}-V$ ed relation, and $\mathrm{V}_{0, \mathrm{dP} / \mathrm{dt}}$ is the volume intercept of the $\mathrm{dP} / \mathrm{dt}_{\max }-$ Ved relation. The position of the $\mathrm{dP} / \mathrm{dt}_{\max }-$ Ved relation in the operating range was calculated by determining Ved associated with $\mathrm{dP} / \mathrm{dt}_{\max }$ of $1000 \mathrm{mmHg} /$ sec:

$$
\mathrm{V}_{\mathrm{t} 000, \mathrm{dP} / \mathrm{dt}}=\mathrm{V}_{0, \mathrm{dP} / \mathrm{dt}}+1000 / \mathrm{dE} / \mathrm{dt}_{\max }
$$




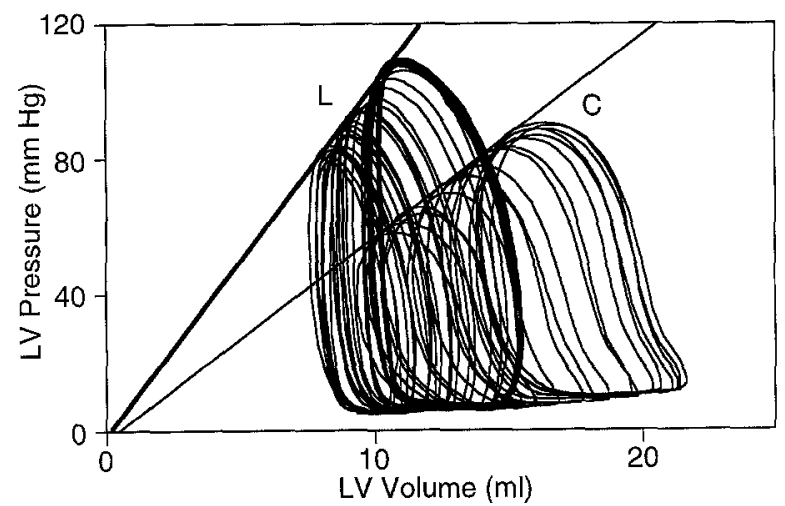

Fig. 1. Representative LV pressure-volume relations derived from a transient preload reduction at 180 minutes after reperfusion in groups $\mathrm{L}$ and $\mathrm{C}$.

Table I. Data on donor and recipient operations

\begin{tabular}{lccc}
\hline & $\begin{array}{c}\text { Group L } \\
(n=6)\end{array}$ & $\begin{array}{c}\text { Group C } \\
(n=6)\end{array}$ & $\begin{array}{c}p \\
\text { Value }\end{array}$ \\
\hline Donor weight (kg) & $15.1 \pm 2.0$ & $15.8 \pm 2.6$ & NS \\
Recipicnt weight (kg) & $14.8 \pm 1.9$ & $15.4 \pm 2.3$ & NS \\
Aortic flow (ml/min) & $1229 \pm 587$ & $1412 \pm 676$ & NS \\
Total ischemic time (h) & $24.5 \pm 1.0$ & $24.4 \pm 1.6$ & NS \\
Implantation time (min) & $68.2 \pm 6.2$ & $69.3 \pm 9.4$ & NS \\
Aortic crossclamp time (min) & $74.5 \pm 6.1$ & $76.8 \pm 9.6$ & NS \\
CPB time (min) & $139.8 \pm 10.5$ & $141.3 \pm 10.3$ & NS
\end{tabular}

Aortic flow was measured at a left atrial pressure of $7 \mathrm{~mm} \mathrm{Hg.} C P B$, cardiopulmonary bypass; $N S$, not significant. Data are presented as mean \pm standard deviation.

LV stiffness (the inverse of compliance) was determined by fitting end-diastolic pressure volume points to the exponential relation:

$$
\text { Ped }=\alpha\left(\mathrm{e}^{\beta \mathrm{Ved}}\right)
$$

in which Ped and Ved are the end-diastolic pressure and volume points, respectively; $\alpha$ is the Ped intercept at $\mathrm{V}=$ $0 \mathrm{ml}$; and $\beta$ is a unit less modulus of chamber stiffness used to describe the degree of curvature of the Ped-Ved relation. ${ }^{28}$

Myocardial energetics. During 150 to 180 minutes after reperfusion, multiple steady-state pressure-volume loops, coronary flow, and arteriovenous oxygen difference data were obtained at various preload volumes for the assessment of myocardial energetics. Preload was reduced in gradual steps by slowing the speed of pump flow. With each load change, all variables were allowed to equilibrate for 5 minutes before recording. Myocardial energetics were assessed by analysis of the relation between the LV myocardial oxygen consumption $\left(\mathrm{MVO}_{2}\right)$ and the $\mathrm{LV}$ systolic pressure-volume area (PVA). The $\mathrm{MVO}_{2}$-PVA relation was described by Suga. ${ }^{24}, 29 \mathrm{MVO}_{2}$ was calculated from the product of coronary flow in milliliters per minutes and coronary arteriovenous oxygen difference in volumes percent. This quantity was divided by the heart
Table II. Comparisons of the hemodynamics of groups $L$ and $C$ at 90,120,150, and 180 minutes after reperfusion

\begin{tabular}{ccccc}
\hline $\begin{array}{c}\text { Time afier } \\
\text { reperfusion }\end{array}$ & $H R$ & $\begin{array}{c}L A P \\
(\mathrm{~mm} \mathrm{Hg})\end{array}$ & $\begin{array}{c}\text { Mean } \mathrm{AoP} \\
(\mathrm{mm} \mathrm{Hg})\end{array}$ & $\begin{array}{c}\text { AoF } \\
(\mathrm{ml} / \mathrm{min})\end{array}$ \\
\hline 90 min & & & & \\
Group L & $142 \pm 7$ & $9.8 \pm 1.1$ & $96.3 \pm 12.9$ & $583 \pm 258$ \\
Group C & $148 \pm 10$ & $10.5 \pm 0.3$ & $85.1 \pm 20.3$ & $407 \pm 184$ \\
$p$ value & $\mathrm{NS}$ & $\mathrm{NS}$ & $\mathrm{NS}$ & $\mathrm{NS}$ \\
120 min & & & & \\
Group L & $141 \pm 8$ & $10.3 \pm 0.5$ & $93.7 \pm 14.2$ & $669 \pm 167$ \\
Group C & $150 \pm 11$ & $10.8 \pm 0.6$ & $87.1 \pm 10.1$ & $466 \pm 143$ \\
$p$ value & $\mathrm{NS}$ & $\mathrm{NS}$ & $\mathrm{NS}$ & $\mathrm{NS}$ \\
150 min & & & & \\
Group L & $143 \pm 6$ & $9.7 \pm 1.2$ & $95.0 \pm 11.4$ & $656 \pm 86$ \\
Group C & $145 \pm 12$ & $10.7 \pm 0.8$ & $68.4 \pm 13.9$ & $331 \pm 135$ \\
$p$ value & $\mathrm{NS}$ & $\mathrm{NS}$ & 0.0046 & 0.0006 \\
180 min & & & & \\
Group L & $143 \pm 6$ & $9.9 \pm 0.6$ & $94.9 \pm 12.0$ & $654 \pm 153$ \\
Group C & $145 \pm 9$ & $10.5 \pm 0.2$ & $69.9 \pm 15.4$ & $325 \pm 163$ \\
$p$ value & $\mathrm{NS}$ & $\mathrm{NS}$ & 0.0106 & 0.0048 \\
\hline
\end{tabular}

$H R$, Heart rate; $L A P$, left atrial pressure; $m A O P$, mean aortic pressure $A O F$, aortic flow; $N S$, not significant. Data are presented as the mean \pm standard deviation.

rate to yield oxygen consumption per beat, $\mathrm{MVO}_{2}$, in milliliters of oxygen per beat. It was normalized with respect to the $\mathrm{LV}$ weight to give $\mathrm{MVO}_{2}$ in milliliters of oxygen per beat per $100 \mathrm{gm}$ of the left ventricle. The oxyhemoglobin percent saturations of the coronary arterial and venous blood were measured with a $\mathrm{pH}$ and blood gas analyzer (model 238, Ciba Corning, Medfield, Mass.), which was calibrated with a galvanometric oxygen content analyzer (Cavitron/Lex $\mathrm{O}_{2}$ Con-K, Cavitron Cardiopulmonary, Anaheim, Calif.).

PVA is the area in the pressure-volume diagram circumscribed by the Pes-Ves relation and Ped-Ved relation curves and the systolic segment of pressure-volume trajectory. The unit of PVA is millimeters of mercury times milliliters. PVA was normalized with respect to the LV weight and expressed in millimeters of mercury times milliliters per beat per $100 \mathrm{gm}$ of the left ventricle. PVA was obtained in steady state contractions with fixed preload.

Coronary vascular resistance. At 60, 90, 120, 150, and 180 minutes after reperfusion, coronary vascular resistance (CVR) was calculated as follows:

$$
\mathrm{CVR}=(\mathrm{ARP} / \mathrm{CF}) \times 80\left(\mathrm{dyn} \cdot \mathrm{sec} / \mathrm{cm}^{5}\right)
$$

where ARP is the aortic root pressure measured by another catheter-tip micromanometer inserted into the ascending aorta and $\mathrm{CF}$ is coronary flow.

Myocardial adenosine triphosphate assessment. Myocardial biopsy was performed to measure the myocardial adenosine triphosphate (ATP) level at the end of ischemia. Biopsy was performed with an 18-gauge biopsy needle (Bard Biopty, C.R. Bard, Inc., Convington, Ga.) at the LV free wall before reperfusion. Samples were rapidly 
Table III. Comparisons of the Pes-Ves, SW-Ved, and $d P / d t_{\text {max }}$ Ved relations for groups $L$ and C at 90,120 , 150 , and 180 minutes after reperfusion

\begin{tabular}{|c|c|c|c|c|}
\hline \multirow{2}{*}{$\begin{array}{l}\text { Time after } \\
\text { reperfusion }\end{array}$} & \multicolumn{4}{|c|}{ Pes-Ves relation } \\
\hline & Ees $(m m H g / m l)$ & $V_{0}, e s(m l)$ & $V_{100}, e s(m l)$ & $r$ \\
\hline \multicolumn{5}{|l|}{$90 \mathrm{~min}$} \\
\hline Group L & $10.0 \pm 2.7$ & $4.3 \pm 6.5$ & $14.9 \pm 7.7$ & $0.985 \pm 0.010$ \\
\hline Group C & $7.9 \pm 4.4$ & $18.8 \pm 12.5$ & $37.7 \pm 24.5$ & $0.986 \div 0.013$ \\
\hline$p$ Value & $\mathrm{NS}$ & 0.0299 & NS & \\
\hline \multicolumn{5}{|l|}{$120 \mathrm{~min}$} \\
\hline Group L & $10.4 \pm 2.7$ & $3.3 \pm 5.7$ & $13.6 \pm 7.0$ & $0.986 \pm 0.011$ \\
\hline Group C & $7.2 \pm 2.8$ & $15.5 \pm 14.5$ & $31.4 \pm 19.5$ & $0.975 \pm 0.022$ \\
\hline$p$ Value & NS & NS & NS & \\
\hline \multicolumn{5}{|l|}{$15 \mathrm{~min}$} \\
\hline Group L & $9.9 \pm 3.6$ & $1.7 \pm 4.6$ & $13.0 \pm 6.2$ & $0.981 \pm 0.022$ \\
\hline Group C & $5.6 \pm 2.8$ & $14.1 \pm 11.9$ & $35.4 \pm 16.7$ & $0.965 \pm 0.042$ \\
\hline$p$ Value & 0.0431 & 0.0377 & 0.0113 & \\
\hline \multicolumn{5}{|l|}{$180 \mathrm{~min}$} \\
\hline Group L & $9.9 \pm 2.9$ & $1.1 \pm 4.0$ & $12.0 \pm 4.2$ & $0.976 \pm 0.024$ \\
\hline Group $\mathrm{C}$ & $5.8 \pm 2.9$ & $14.3 \pm 13.1$ & $35.0 \pm 19.2$ & $0.957 \pm 0.040$ \\
\hline$p$ Value & 0.0345 & 0.0390 & 0.0169 & \\
\hline \multirow{2}{*}{$\begin{array}{l}\text { Time after } \\
\text { reperfusion }\end{array}$} & \multicolumn{4}{|c|}{$S W$-Ved relation } \\
\hline & Msw (mm Hg) & $V_{o}, s w(m l)$ & $V_{500}, 5 w(\mathrm{ml})$ & $r$ \\
\hline \multicolumn{5}{|l|}{$90 \min$} \\
\hline Group L & $54.6 \pm 15.6$ & $10.3 \pm 6.5$ & $20.2 \pm 6.7$ & $0.976 \pm 0.015$ \\
\hline Group C & $52.2 \pm 22.2$ & $32.4 \pm 20.5$ & $43.5 \pm 22.7$ & $0.957 \pm 0.060$ \\
\hline$p$ Value & NS & 0.0306 & 0.0361 & \\
\hline \multicolumn{5}{|l|}{$120 \mathrm{~min}$} \\
\hline Group L & $60.7 \pm 14.2$ & $9.9 \pm 6.4$ & $18.5 \pm 5.4$ & $0.983 \pm 0.009$ \\
\hline Group C & $47.0 \pm 23.9$ & $26.3 \pm 17.8$ & $39.1 \pm 19.2$ & $0.962 \pm 0.020$ \\
\hline$p$ Value & NS & NS & 0.0295 & \\
\hline \multicolumn{5}{|l|}{$150 \mathrm{~min}$} \\
\hline Group L & $60.6 \pm 11.4$ & $9.0 \pm 4.5$ & $17.6 \pm 5.1$ & $0.985 \pm 0.009$ \\
\hline Group C & $38.1 \pm 10.7$ & $28.9 \pm 18.5$ & $42.9 \pm 17.1$ & $0.920 \pm 0.056$ \\
\hline$p$ Value & 0.0055 & 0.0287 & 0.0060 & \\
\hline \multicolumn{5}{|l|}{$180 \mathrm{~min}$} \\
\hline Group L & $61.3 \pm 17.6$ & $8.3 \pm 3.6$ & $17.1 \pm 2.4$ & $0.982 \pm 0.011$ \\
\hline Group C & $42.7 \pm 9.1$ & $28.9 \pm 19.5$ & $41.0 \pm 19.6$ & $0.928 \pm 0.080$ \\
\hline \multirow[t]{2}{*}{$p$ Value } & 0.0438 & $0 . \overline{0297}$ & $0 . \overline{0141}$ & \\
\hline & \multicolumn{4}{|c|}{$d P / d t_{\text {max }}-$ Ved relation } \\
\hline $\begin{array}{l}\text { Time after } \\
\text { reperfusion }\end{array}$ & $\begin{array}{c}d E / d t_{\max } \\
(m m \mathrm{Hg} /(\mathrm{sec} \cdot \mathrm{ml}))\end{array}$ & $V_{0, d P / d t}(\mathrm{ml})$ & $V_{1000, d P / d t}(\mathrm{ml})$ & $r$ \\
\hline \multicolumn{5}{|l|}{$90 \mathrm{~min}$} \\
\hline Group L & $79.7 \pm 25.8$ & $2.7 \pm 5.8$ & $15.9 \pm 7.8$ & $0.923 \pm 0.140$ \\
\hline Group C & $66.6 \pm 33.8$ & $18.7 \pm 18.2$ & $40.5 \pm 26.1$ & $0.975 \pm 0.016$ \\
\hline$p$ Value & NS & NS & NS & \\
\hline \multicolumn{5}{|l|}{$120 \mathrm{~min}$} \\
\hline Group L & $82.9 \pm 28.7$ & $2.1 \pm 5.8$ & $14.9 \pm 7.9$ & $0.924 \pm 0.141$ \\
\hline Group C & $60.8 \pm 22.6$ & $15.6 \pm 18.8$ & $35.0 \pm 23.4$ & $0.969 \pm 0.018$ \\
\hline$p$ Value & NS & NS & NS & \\
\hline \multicolumn{5}{|l|}{$150 \mathrm{~min}$} \\
\hline Group L & $75.7 \pm 30.9$ & $-0.2 \pm 5.6$ & $14.4 \pm 7.6$ & $0.927 \pm 0.142$ \\
\hline Group C & $44.4 \pm 13.1$ & $12.0 \pm 16.8$ & $36.2 \pm 16.7$ & $0.948 \pm 0.032$ \\
\hline$p$ Value & 0.0460 & $\mathrm{NS}$ & 0.0154 & \\
\hline \multicolumn{5}{|l|}{$180 \mathrm{~min}$} \\
\hline Group L & $82.7 \pm 30.4$ & $-1.5 \pm 2.4$ & $12.3 \pm 4.9$ & $0.977 \pm 0.014$ \\
\hline Group C & $41.3 \pm 12.7$ & $9.3 \pm 17.2$ & $35.9 \pm 20.8$ & $0.951 \div 0.036$ \\
\hline$p$ Value & 0.0116 & NS & 0.0221 & \\
\hline
\end{tabular}

LV, left ventricular; Pes, LV end-systolic pressure; Ves, end-systolic volume; Ees, slope of Pes-Ves relation; $V_{0}$, es, volume axis intercept of Pes-Ves relation; $V_{\text {too }}, e s$, Ves associated with Pes of $100 \mathrm{~mm} \mathrm{Hg} ; r$, mean value of correlation coefficient; $N S$, not significant; SW, LV stroke work; Ved, end-diastolic volume; Msw, slope of SW-Ved relation; $V_{0,5 W}$ volume intercept of SW-Ved relation; $V_{500, S W}$ Ved associated with $\mathrm{SW}$ of $500 \mathrm{ml} \cdot \mathrm{mm} \mathrm{Hg}$; $d P / d t_{m a n}$ maximum rate

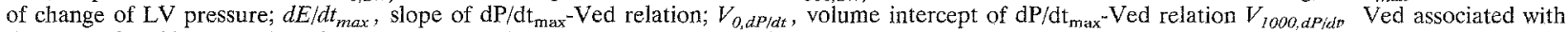
$\mathrm{dP} / \mathrm{dt} \max$ of $1,000 \mathrm{~mm} \mathrm{Hg} / \mathrm{sec}$. Data are presented as mean \pm standard deviation. 
Table IV. Comparisons of the Ped-Ved relation between groups $L$ and $C$ at $90,120,150$, and 180 minutes after reperfusion

\begin{tabular}{|c|c|c|c|}
\hline $\begin{array}{l}\text { Time after } \\
\text { reperfusion }\end{array}$ & $\beta$ & $\alpha$ & $r$ \\
\hline \multicolumn{4}{|l|}{$90 \min$} \\
\hline Group L & $0.098 \pm 0.020$ & $1.72 \pm 0.81$ & $0.986 \pm 0.013$ \\
\hline Group C & $0.107 \pm 0.029$ & $1.26 \pm 0.43$ & $0.992 \pm 0.005$ \\
\hline$p$ Value & NS & NS & \\
\hline \multicolumn{4}{|l|}{$120 \mathrm{~min}$} \\
\hline Group L & $0.103 \pm 0.020$ & $1.65 \pm 0.91$ & $0.985 \pm 0.013$ \\
\hline Group C & $0.103 \pm 0.023$ & $1.30 \pm 0.39$ & $0.988 \pm 0.012$ \\
\hline$p$ Value & NS & NS & \\
\hline \multicolumn{4}{|l|}{$150 \mathrm{~min}$} \\
\hline Group L & $0.109 \pm 0.022$ & $1.65 \pm 0.91$ & $0.987 \pm 0.014$ \\
\hline Group C & $0.094 \pm 0.032$ & $1.28 \pm 0.48$ & $0.973 \pm 0.037$ \\
\hline$p$ value & NS & NS & \\
\hline \multicolumn{4}{|l|}{$180 \mathrm{~min}$} \\
\hline Group L & $0.109 \pm 0.038$ & $1.27 \pm 0.59$ & $0.990 \pm 0.006$ \\
\hline Group C & $0.096 \pm 0.034$ & $1.34 \pm 0.50$ & $0.960 \pm 0.060$ \\
\hline$p$ Value & NS & NS & \\
\hline
\end{tabular}

Ped, LV end-diastolic pressure; Ved, end-diastolic volume; $\beta$, degree of curvature of Ped-Ved relation; $\alpha$, volume intercept of Ped-Ved relation; $\mathrm{r}$, mean value of correlation coefficient; NS, not significant. Data are presented as mean \pm standard deviation.

frozen with liquid nitrogen and preserved in liquid nitrogen until analysis. ATP was measured with the use of high-pressure liquid chromatography as previously described. ${ }^{30}$

Serum chemistry. Serum creatine kinase MB (CK-MB) isoenzyme and lipid peroxide levels were measured 180 minutes after reperfusion. Serum lipid peroxide levels were measured by a methylene blue derivative method. ${ }^{31}$

Myocardial water content. LV free wall specimens taken after experiments were weighed just after collection (wet weight) and after 24 hours' desiccation (dry weight). The myocardial water content was calculated by the following formula:

Myocardial water content $=$

(wet weight - dry weight)/wet weight $\times 100(\%)$

Statistical analysis. Results are presented as the mean \pm one standard deviation. The Student's $t$ test was used to analyze the differences. A $p$ value less than 0.05 was considered significant.

Animal care. All animals have received humane care in compliance with the "Principles of Laboratory Animal Care" formulated by the National Society for Medical Research and the "Guide for the Care and Use of Laboratory Animals" prepared by the Institute of Laboratory Animal Resources and published by the National Institutes of Health (NIH Publication No. 86-23, revised 1985). This experiment was reviewed by the Committee of the Ethics on Animal Experiment in Faculty of Medicine, Kyushu University, and carried out under the control of the Guidelines for Animal Experiment in Faculty of Medicine, Kyushu University, and The Law (No. 105) and Notification (No. 6) of the Government.
Table V. Comparisons of the $\mathrm{MVO}_{2}-\mathrm{PVA}$ relation for groups $L$ and $C$

\begin{tabular}{lccc}
\hline & Slope $\left(\times 10^{-5}\right)$ & Intercept $\left(\times 10^{-2}\right)$ & $r$ \\
\hline Group L & $1.02 \pm 0.60$ & $1.30 \pm 0.88$ & $0.950 \pm 0.098$ \\
Group C & $0.94 \pm 0.78$ & $1.17 \pm 0.32$ & $0.933 \pm 0.095$ \\
$p$ Value & NS & NS &
\end{tabular}

$M V \mathrm{O}_{2}$, Myocardial oxygen consumption; $P V A$, systolic pressure-volume area; $r$, mean value of correlation coefficient; $N S$, not significant. Data are presented as mean \pm standard deviation.

\section{Results}

All the dogs in both groups were successfully disconnected from cardiopulmonary bypass. No significant difference was observed between the two groups in regard to donor weight, recipient weight, and aortic flow measured at the left atrial pressure of $7 \mathrm{~mm} \mathrm{Hg}$. Mean ischemic preservation times (total ischemic time and implantation time) were similar for the two groups. Aortic crossclamp and cardiopulmonary bypass times were also similar for the two groups (Table I).

Conventional hemodynamic variables. Conventional hemodynamic variables at $90,120,150$, and 180 minutes after reperfusion are provided in Table II. Mean aortic pressure and aortic flow in group L were higher than those in group C at 150 and 180 minutes after reperfusion.

Ventricular function. Representative multiple LV pressure-volume loops of two groups are shown in Fig. 1. Parameters of systolic ventricular function at $90,120,150$, and 180 minutes after reperfusion are provided in Table III. Although the differences of Ees between the two groups were not significant at 90 and 120 minutes after reperfusion, Ees in group $\mathrm{C}$ decreased gradually, and the differences reached statistical significance at 150 and $180 \mathrm{~min}-$ utes after reperfusion. Similar significant differences were observed in $M_{S w}$ and $\mathrm{dE} / \mathrm{dt}_{\text {max }}$ between groups $\mathrm{L}$ and $\mathrm{C}$ at 150 and 180 minutes after reperfusion. The differences of $\mathrm{V}_{0}$, es and $\mathrm{V}_{0, \mathrm{sw}}$ between the two groups were significant at 90,150 , and 180 minutes after reperfusion. All three relations for group L were shifted toward the left in the operating range compared with group $C$, manifested by $V_{100}$, es,

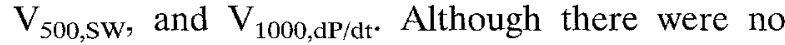
significant differences between the two groups up to 120 minutes after reperfusion, $V_{100, \text { es }}$ and $V_{1000, d P / d t}$ for group $\mathrm{L}$ was significantly lower than the values for group $\mathrm{C}$ at 150 and 180 minutes after reperfusion. At each time point, there were significant differences in $V_{500, S w}$ between the two groups. 


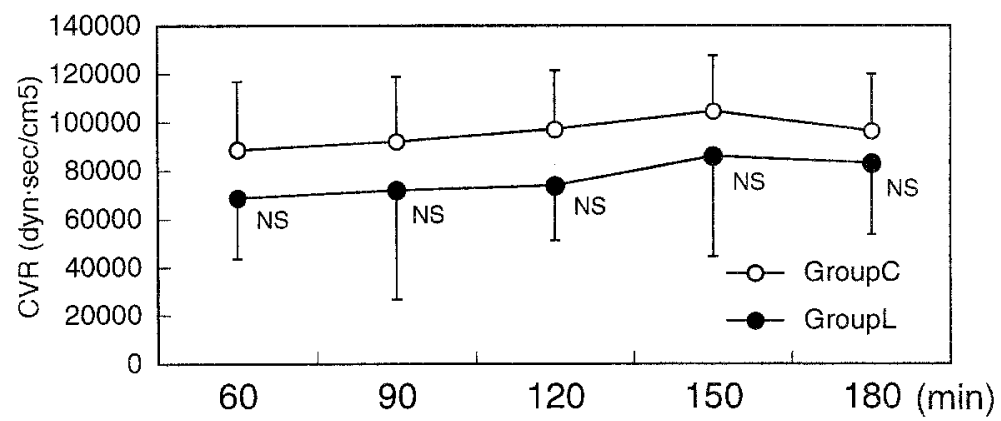

Fig. 2. The changes of CVR at $90,120,150$, and 180 minutes after reperfusion in groups $L$ and C. Data are presented as the mean \pm 1 standard deviation. $N S$, Not significant.

Diastolic ventricular function parameters at 90 , 120,150 , and 180 minutes after reperfusion are provided in Table IV. There were no significant differences in the degree of curvature that reflected end-diastolic chamber stiffness, $\beta$, and the volume intercept of Ped-Ved relation, $\alpha$, between groups $\mathrm{L}$ and $\mathrm{C}$.

Myocardial energetics. Differences in the $\mathrm{MVO}_{2}-$ PVA relation between groups $\mathrm{L}$ and $\mathrm{C}$ are shown in Table V. The slope and intercept of the $\mathrm{MVO}_{2}$-PVA relation were similar for the two groups.

CVR. The changes of CVR at 90,120,150, and 180 minutes after reperfusion are shown in Fig. 2. CVR in group $\mathrm{L}$ was lower than that in group $\mathrm{C}$ throughout the assessment period, but the difference between the two groups did not reach statistical significance.

Myocardial ATP. ATP level at the end of ischemia in group L was significantly higher than that in group C: $28.09 \pm 15.17 \mu \mathrm{mol} / \mathrm{gm}$ and $12.59 \pm 2.68$ $\mu \mathrm{mol} / \mathrm{gm}(p=0.0334)$, respectively (Fig. 3).

Serum chemistry. Serum CK-MB and lipid peroxide levels at 180 minutes after reperfusion in group $\mathrm{L}$ were significantly lower than those in group $\mathrm{C}$ (Fig. 4). The values of serum CK-MB level in groups $\mathrm{L}$ and $\mathrm{C}$ were $88.0 \pm 72.8 \mathrm{ng} / \mathrm{ml}$ and $292.2 \pm$ $162.5 \mathrm{ng} / \mathrm{ml}(p=0.0185)$, respectively. The values of serum lipid peroxide level in groups $\mathrm{L}$ and $\mathrm{C}$ were $0.05 \pm 0.39 \mathrm{nmol} / \mathrm{ml}$ and $1.74 \pm 1.77 \mathrm{nmol} / \mathrm{ml}(p=$ $0.0455)$, respectively.

Myocardial water content. There was no significant difference in the myocardial water content between groups $\mathrm{L}$ and C: $78.9 \% \pm 2.5 \%$ and $78.9 \%$ $\pm 1.2 \%(p=0.9473)$, respectively.

\section{Discussion}

Lipid peroxidation involving polyunsaturated fatty acids in cell membranes is a free radical- induced chain reaction initiated by the hydroxyl radical formed during the ischemia-reperfusion period. Lipid peroxidation severely damages the cell membrane, produces loss of fluidity, and triggers the breakdown of membrane secretory functions and transmembrane ionic gradients. ${ }^{32}$

Lazaroids are 21-aminosteroids that prevent lipid peroxidation without obvious glucocorticoid or mineralocorticoid side effects. ${ }^{11,12}$ U74500A, one agent of the lazaroid family, is a potent inhibitor of iron-catalyzed lipid peroxidation. ${ }^{12}$ U74500A has been effective in a variety of models of ischemiareperfusion injury. ${ }^{15-17,33-38}$ Killinger and colleagues, ${ }^{38}$ who used an umbilical vein endothelial cell culture model, studied the effects of lazaroids as additives to preservation solutions. They reported that the addition of lazaroids to organ preservation solutions greatly improved endothelial cell viability. $\mathrm{We}^{15}$ previously reported that the inhibition of lipid peroxidation by the pretreatment with U74500A prevented myocardial contracture and preserved LV function after 35 minutes of normothermic global ischemia in an isolated blood-perfused rabbit heart preparation. ${ }^{15}$ We also reported the beneficial effects of the prevention of lipid peroxidation with U74500A for 24-hour heart preservation in an isolated blood-perfused rabbit working heart model. ${ }^{16}$

Because experimentation with a large animal model was mandatory for the clinical application of this agent, we used a canine orthotopic heart transplantation model. In the current study, we demonstrated the beneficial effect of the inhibition of lipid peroxidation by administering U74500A for canine heart grafts preserved for 24 hours. Throughout the 180-minute assessment period after reperfusion, the dogs treated with U74500A showed better systolic ventricular function than did dogs without the U74500A treatment. The serum CK-MB and lipid 


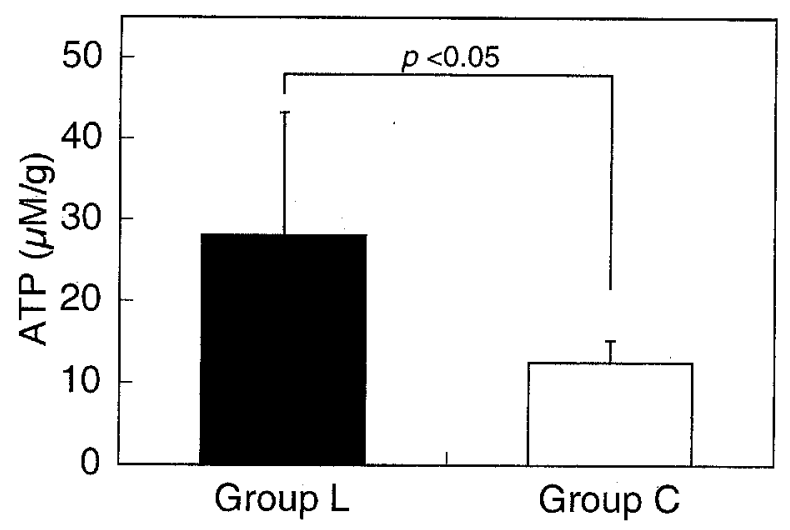

Fig. 3. ATP level at the end of ischemia in groups $L$ and C. Data are presented as the mean \pm 1 standard deviation.

peroxide levels in the dogs treated with U74500A were lower than those of dogs without the U74500A treatment. Myocardial ATP levels at the end of ischemia in donor hearts treated with U74500A remained higher than those in donor hearts without the U74500A treatment.

U74500A was administered intravenously to donor dogs before preservation and to recipient dogs before reperfusion, because the lazaroid U74500A is not inherently soluble in UW solution. U74500A is not soluble at neutral or alkaline $\mathrm{pH}$, which is the case for UW solution. Systemically administered U74500A was equally effective to that administered as an additive to the preservation solution. The dosage of $10 \mathrm{mg} / \mathrm{kg}$ was chosen because our preliminary experiment with a $5 \mathrm{mg} / \mathrm{kg}$ concentration of U74500A showed no substantial benefit in cardiac function. Further study is warranted to show the dose-response effect of U74500A on preservation if the agent is to be applied clinically.

We selected UW solution for the preservation solution because of reports that documented the superiority of UW solution for heart preservation. ${ }^{39-41}$ We have reported that storing the heart in intracellular-type solution provided best results, but to prevent coronary vasoconstriction during the infusion of intracellular-type solution, extracellulartype solution (crystalloid cardioplegia) should be used to arrest the heart. ${ }^{42}$ We have observed that arresting the heart with UW solution caused remarkable coronary vasoconstriction (unpublished data). In this study, we arrested the heart by an extracellular-type crystalloid cardioplegic solution to prevent UW solution-induced vasoconstriction.

The temperature for preservation was set to $1^{\circ} \mathrm{C}$
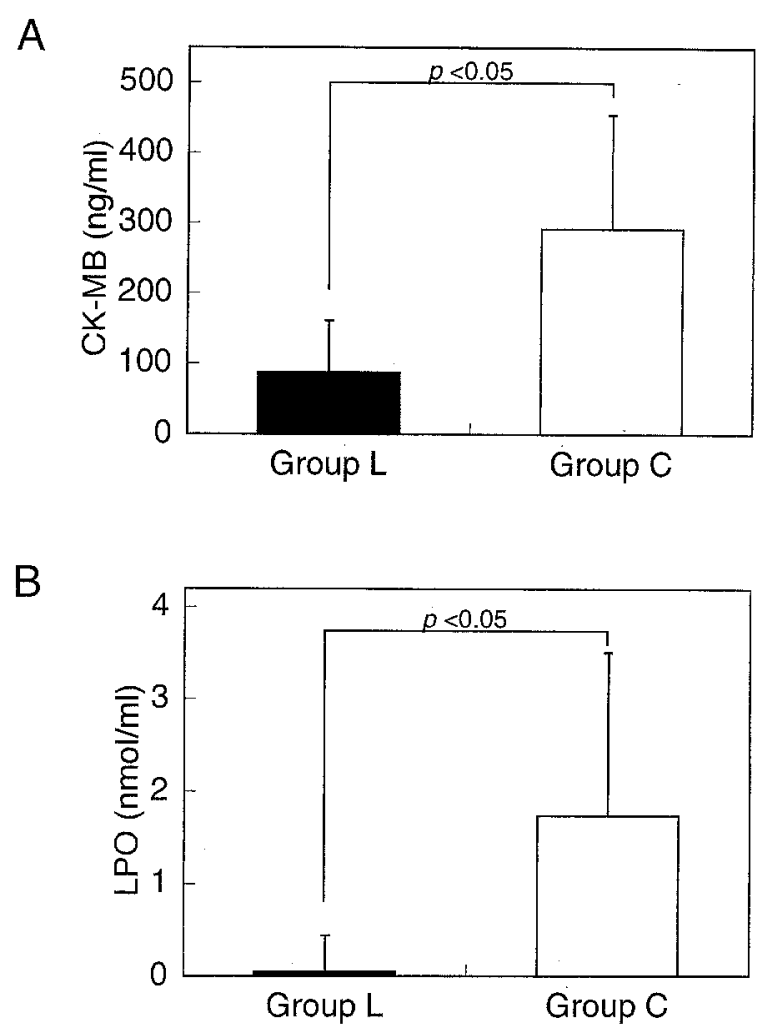

Fig. 4. CK-MB (A) and lipid peroxide (LPO) levels (B) were measured 180 minutes after reperfusion in groups $\mathbf{L}$ and C. Data are presented as the mean \pm 1 standard deviation.

because of studies reporting that the optimal temperature for UW solution was below $10^{\circ} \mathrm{C} .^{43}$ The temperature was easily maintained by immersing the plastic bag containing the graft into ice slush. The cardiac preservation period of 24 hours was selected because our preliminary reports showed no difference between the two groups after 6 or 12 hours of preservation in UW solution.

Conventional hemodynamic variables (e.g., mean aortic pressure, aortic flow) of dogs treated with U74500A were superior to those of dogs without the U74500A treatment. The indices of systolic ventricular function, Ees, $\mathrm{M}_{\mathrm{SW}}$, and $\mathrm{dE} / \mathrm{dt}_{\max }$ of dogs treated with U74500A were superior to those of dogs without the U74500A treatment. Although there was no difference in LV end-diastolic chamber stiffness between the two groups, LV pressurevolume loops of dogs treated with U74500A were shifted significantly toward the left compared with those of dogs without the U74500A treatment. The inhibition of lipid peroxidation by the administration of the lazaroid U74500A preserved ventricular 
function after 24 hours of ischemia in this canine orthotopic heart transplantation model.

Although the difference was not significant, CVR after reperfusion of dogs treated with U74500A tended to be lower in this study. Mankad and colleagues $^{44}$ reported that UW solution caused endothelial dysfunction in the isolated rat heart preparation. Pearl and colleagues ${ }^{45}$ showed the loss of endothelium-dependent vasodilatation and nitric oxide release after myocardial protection with UW solution. The fact that the pretreatment of U74500A tended to keep CVR at a lower level might indicate the effect of preservation of coronary endothelial function.

The ATP level of dogs administered U74500A was maintained at a high level at the end of the 24 -hour ischemia period in this study. $\mathrm{We}^{15}$ previously reported that pretreatment with U74500A prevented myocardial contracture during ischemia in an isolated rabbit heart preparation. These results suggest that $\mathrm{U} 74500 \mathrm{~A}$ has some cardioprotective effect during ischemia. Although lower serum CK-MB and lipid peroxide levels after reperfusion in U74500A-treated dogs indicated the inhibition of lipid peroxidation, the high ATP level at the end of ischemia and the prevention of myocardial contracture during ischemia cannot be fully explained by the inhibition of lipid peroxidation. Some other mechanisms of U74500A were indicated from these results.

The limitation of our experimental model was that the assessment period was restricted to $\mathbf{1 8 0}$ minutes after reperfusion, because right heart bypass with a membrane oxygenator was used. To examine the long-term effect of U74500A, we measured conventional hemodynamic parameters without a right heart bypass. In this preliminary study, the heart treated with U74500A was able to maintain adequate aortic flow for up to 6 hours after reperfusion.

In this study, the technique of heart transplantation was designed as much as possible to retain clinical relevance. Adding U74500A to the current heart-harvesting protocol may extend the limit of the safe preservation period. A 24-hour heart preservation would be possible by combining the available techniques and the prevention of lipid peroxidation with the lazaroid U74500A.

The inhibition of lipid peroxidation by administering the lazaroid U74500A prevented lipid peroxidation and preserved systolic ventricular function after 24 hours of ischemia in an orthotopic canine heart transplantation model. These results indicate that $\mathrm{U} 74500 \mathrm{~A}$ is a promising agent for cardiac allograft preservation.

U74500A and CS-4 solutions were provided by The Upjohn Company (Kalamazoo, Mich.).

\section{REFERENCES}

1. Hosenpud JD, Novick RJ, Breen TJ, Keck B, Daily P. The Registry of the International Society for Heart and Lung Transplantation: twelfth official report-1995. J Heart Lung Transplant 1995;14:805-15.

2. Guarnieri C, Flamigni F, Caldarera CM. Role of oxygen in the cellular damage induced by re-oxygenation of hypoxic heart. J Mol Cell Cardiol 1980;12:797-808.

3. Rao PS, Cohen MV, Mueller HS. Production of free radicals and lipid peroxides in early experimental myocardial ischemia. J Mol Cell Cardiol 1983;15:713-6.

4. Meerson FZ, Kagan VE, Kozlov YP, Belkina LM, Arkhipenko YV. The role of lipid peroxidation in pathogenesis of ischemic damage and the antioxidant protection of the heart. Basic Res Cardiol 1982;77:465-85.

5. Jolly SR, Kane WJ, Bailie MB, Abrams GD, Lucchesi BR. Canine myocardial reperfusion injury: its reduction by the combined administration of superoxide dismutase and catalase. Circ Res 1984:54:277-85.

6. Gross GJ, Farber NE, Hardman HF, Warltier DC. Beneficial actions of superoxide dismutase and catalase in stunned myocardium of dogs. Am J Physiol 1986;250:H372-7.

7. Stewart JR, Crute SL, Loughlin V, Hess ML, Greenfield LJ. Prevention of free radical-induced myocardial reperfusion injury with allopurinol. J Thorac Cardiovasc Surg 1985;90:6872.

8. Menasché P, Grousset C, Mouas C, Piwnica A. A promising approach for improving the recovery of heart transplants: prevention of free radical injury through iron chelation by deferoxamine. J Thorac Cardiovasc Surg 1990;100:13-21.

9. Stewart JR, Blackwell WH, Crute SL, Loughlin V, Greenfield LJ, Hess ML. Inhibition of surgically induced ischemia/ reperfusion injury by oxygen free radical scavengers. $\mathbf{J}$ Thorac Cardiovasc Surg 1983;86:262-72.

10. Bernier M, Hearse DJ, Manning AS. Reperfusion-induced arrhythmias and oxygen-derived free radicals: studies with "anti-free radical" interventions and a free radical-generating system in the isolated perfused rat heart. Circ Res 1986;58:331-40.

11. Ryan TP, Steenwyk RC, Pearson PG, Petry TW. Inhibition of in vitro lipid peroxidation by 21 -aminosteroids: evidence for differential mechanisms. Biochem Pharmacol 1993;46:877-84.

12. Braughler JM, Pregenzer JF, Chase RL, Duncan LA, Jacobsen EJ, McCall JM. Novel 21-amino steroids as potent inhibitors of iron-dependent lipid peroxidation. J Biol Chem 1987;262:10438-40.

13. Hall ED, Yonkers PA. Attenuation of postischemic cerebral hypoperfusion by the 21-aminosteroid U74006F. Stroke 1988;19:340-4.

14. Braughler JM, Hall ED, Jacobsen EJ, McCall JM, Means ED. The 21-aminosteroids: potent inhibitors of lipid peroxidation for the treatment of central nervous system trauma and ischemia. Drug Future 1989;14:143-52.

15. Miyamoto K, Morita S, Nishida T, et al. Pretreatment with 
lazaroid (U-74500A) prevents ischemic and reperfusion injury in blood-perfused rabbit hearts. Surg Forum 1994;45: 230-2.

16. Nishida T, Morita S, Miyamoto K, et al. The effect of lazaroid (U74500A), a novel inhibitor of lipid peroxidation, on 24hour heart preservation: a study based on a working model using cross-circulated blood perfused rabbit hearts. Transplantation 1996;61:194-9.

17. Tanoue Y, Morita S, Ochiai Y, et al. Successful twenty-fourhour canine lung preservation with the lazaroid U74500A. J Heart Lung Transplant 1996;15:43-50.

18. Kinoshita K, Oe M, Tokunaga K. Superior protective effect of low-calcium, magnesium-free potassium cardioplegic solution on ischemic myocardium: clinical study in comparison with St. Thomas' Hospital solution. J Thorac Cardiovasc Surg 1991;101:695-702.

19. Tanaka N, Nozawa T, Yasumura Y, Futaki S, Hiramoi K, Suga H. Contractility to minimize oxygen consumption for constant work in dog left ventricle. Heart Vessels 1990;6:9-20.

20. Nozawa $T$, Yasumura $Y$, Futaki S, et al. Relation between oxygen consumption and pressure-volume area of in situ dog heart. Am J Physiol 1987;253:H31-40.

21. Bann J, van der Velde ET, de Bruin HG, et al. Continuous measurement of left ventricular volume in animals and humans by conductance catheter. Circulation 1984;70:812-23.

22. Applegate RJ, Cheng CP, Little WC. Simultaneous conductance catheter and dimension assessment of left ventricle volume in the intact animal. Circulation 1990;81:638-48.

23. Kelly RP, Tunin R, Kass DA. Effect of reduced aortic compliance on cardiac efficiency and contractile function of in situ canine left ventricle. Circ Res 1992;71:490-502.

24. Suga H. Ventricular energetics. Physiol Rev 1990;70:247-77.

25. Glower DD, Spratt JA, Snow ND, et al. Linearity of the Frank-Starling relationship in the intact heart: the concept of preload recruitable stroke work. Circulation 1985;71:994-1009.

26. Little WC. The left ventricular $\mathrm{dP} / \mathrm{dt}_{\max }$-end-diastolic volume relation in closed-chest dogs. Circ Res 1985;56:808-15.

27. Little WC, Cheng CP, Mumma M, Igarashi Y, VintenJohansen J, Johnston WE. Comparison of measures of left ventricular contractile performance derived from pressurevolume loops in conscious dogs. Circulation 1989;80:1378-87.

28. Gaasch WH, Battle WE, Oboler AA, Banas JS Jr, Levine HJ. Left ventricular stress and compliance in man: with special reference to normalized ventricular function curves. Circulation 1972;45:746-62.

29. Suga H, Hisano R, Goto Y, Yamada O, Igarashi Y. Effect of positive inotropic agents on the relation between oxygen consumption and systolic pressure volume area in canine left ventricle. Circ Res 1983;53:306-18.

30. Masuda M, Yonenaga K, Shiki K, Morita S, Kohno H, Tokunaga K. Myocardial protection in coronary occlusion by retrograde cardioplegic perfusion via the coronary sinus in dog: preservation of high-energy phosphates and regional function. J Thorac Cardiovasc Surg 1986;92:255-63.

31. Ohishi N, Ohkawa H, Miike A, Tatano T, Yagi K. A new assay method for lipid peroxides using a methylene blue derivative. Biochem Int 1985;10:205-11.
32. Southorn PA, Powis G. Free radicals in medicine. I. Chemical nature and biologic reactions. Mayo Clin Proc 1988;63: 381-9.

33. Aeba R, Killinger WA, Keenan RJ, et al. Lazaroid U74500A as an additive to University of Wisconsin solution for pulmonary grafts in the rat transplant model. J Thorac Cardiovasc Surg 1992;104:1333-9.

34. Ciuffi M, Gentilini G, Franchi-Micheli S, Zilletti L. Effect of 21-aminosteroid U74500A on rat brain cortex lipid peroxidation induced "in vivo" by iron-carbohydrate. Biochem Pharmacol 1994;47:2181-6.

35. Levitt MA, Sievers RE, Wolfe CL. Reduction of infarct size during myocardial ischemia and reperfusion by lazaroid U-74500A, a nonglucocorticoid 21-aminosteroid. J Cardiovasc Pharmacol 1994;23:136-40.

36. Jacobsson J, Sundberg R, Rilo HLR, Gasbarrini A, Starzl TE, Van-Thiel D. Protective effects of the lazaroid U74500A and lidoflazine on liver preservation with UW solution. Transpl Int 1993;6:281-4.

37. Haynes J Jr, Seibert A, Bass JB, Taylor AE. U74500A inhibition of oxidant-mediated lung injury. Am J Physiol 1990;259:H144-8.

38. Killinger WA Jr, Dorofi DB, Keagy BA, Johnson G Jr. Improvement of endothelial cell viability at $4^{\circ} \mathrm{C}$ by addition of lazaroid U74500A to preservation solutions. Transplantation 1992;53:983-6.

39. Jeevanandam V, Barr ML, Auteri JS, et al. University of Wisconsin solution versus crystalloid cardioplegia for human donor heart preservation: a randomized blinded prospective clinical trial. J Thorac Cardiovase Surg 1992;103:194-9.

40. Stein DG, Drinkwater DC Jr, Laks H, et al. Cardiac preservation in patients undergoing transplantation: a clinical trial comparing University of Wisconsin solution and Stanford solution. J Thorac Cardiovasc Surg 1991;102:657-65.

41. Kawai A, Morita S, Kormos RL, et al. A clinical trial comparing University of Wisconsin solution and cold cardioplegic solution with load-independent mechanical parameters. J Heart Lung Transplant 1994;13:150-6.

42. Kohno H, Shiki K, Ueno Y, Tokunaga K. Cold storage of the rat heart for transplantation: two types of solution required for optimal preservation. J Thorac Cardiovasc Surg 1987;93: 86-94.

43. Amrani M, Ledingham S, Jayakumar J, et al. Detrimental effects of temperature on the efficacy of the University of Wisconsin solution when used for cardioplegia at moderate hypothermia: comparison with the St. Thomas Hospital solution at $4^{\circ} \mathrm{C}$ and $20^{\circ} \mathrm{C}$. Circulation 1992;86(Suppl): II280-8.

44. Mankad P, Slavik Z, Yacoub M. Endothelial dysfunction caused by University of Wisconsin preservation solution in the rat heart: the importance of temperature. J Thorac Cardiovasc Surg 1992;104:1618-24.

45. Pearl JM, Laks H, Drinkwater DC, et al. Loss of endothelium-dependent vasodilatation and nitric oxide release after myocardial protection with University of Wisconsin solution. J Thorac Cardiovase Surg 1994;107:257-64. 